\title{
Research On Calculation Method of Serpentine Pipe Bend
}

\author{
Xuchen Zhu ${ }^{1}$, Yannan $\mathrm{Du}^{1,2^{*}}$, Bin Ren ${ }^{1,2}$, Xiaoying Tang ${ }^{1,2}$, Zhigang Yang ${ }^{3}$, Jie Yang ${ }^{3}$. \\ ${ }^{1}$ Shanghai Institute of Special Equipment Inspection and Technical Research, Putuo District, Shanghai, 200062, China \\ ${ }^{2}$ National Heat Exchanger Product Quality Inspection Center, Jinshan District, Shanghai, 201518, China \\ ${ }^{3}$ Shanghai Electric Power Generation Equipment Co. Ltd. Power Station Auxiliary Equipment Plant, Shanghai, 200090, China
}

\begin{abstract}
Because of its structural characteristics, the serpentine high-pressure heater has thinner tubesheet compared with the traditional U-tube high-pressure heater, which solves the bottleneck of tubesheet manufacturing and becomes an important auxiliary machine for millions of secondary reheating units in the future. In this paper, the typical working conditions are selected, and the bending design methods of domestic and foreign serpentine tubes are adopted respectively. The results show that compared with Chinese standards, the bending can be thinned. Subsequent tests and finite element simulations verify the reliability of foreign methods and explore the optimization design methods of domestic serpentine tubes.
\end{abstract}

\section{Introduction}

With the deep development of energy in the world and the improvement of environmental protection requirements in the market, coal-fired power generation equipment is gradually developing in depth towards high parameters, large capacity, low heat consumption and environmental protection[1-3]. As an important auxiliary machine to improve thermal economy, high-pressure heater is an important part of million-grade secondary reheating unit. The biggest difference between snakeshaped pipe height adding and U-tube pipe height adding is that the inlet header replaces the inlet chamber and tubesheet of U-tube pipe height adding, and its thickness is about one tenth of that of tubesheet, and it has better thermal shock resistance, higher temperature rise speed limit and more operation times under off-design conditions. However, compared with U-tube pipe, snakeshaped pipe has larger diameter, larger wall thickness and larger thermal resistance, which has become an unfavorable factor restricting its application and popularization. Domestic manufacturers with the ability to design and manufacture double-row high-pressure heaters for millions of secondary reheating units mainly include Shanghai Electric Power Station Equipment Co., Ltd., Shanghai Power Station Auxiliary Equipment Factory, Suzhou Tianwo Technology Co., Ltd., Harbin Boiler Factory Co., Ltd., Hangzhou Boiler Manufacturing Co., Ltd., etc. Foreign manufacturers that can produce such high-pressure heaters with large capacity and high parameters include Germany's Hamon Sobeleco, Barker-Toure (BDT) and France's Alstom, etc. These manufacturers have the performance of designing and manufacturing a single $100 \%$ capacity high-pressure heater for millions of units. Since millions of secondary reheating units are mainly in China, there are no practical engineering cases of single-row high-pressure heater operation of millions of secondary reheating units at present, and there are obvious differences between the design methods of foreign serpentine tubes and Chinese standards. Therefore, China has not formulated the calculation standard of serpentine tube bending, and refers to the bending method of U-tube tubes. In this paper, the typical working conditions are selected, and the methods of GB/T 151-2014[4] Heat Exchanger and EN12952 Appendix A[5] are used to calculate the bend, so as to explore the difference of strength check of serpentine bend at home and abroad, and to explore the optimization way of serpentine bend in China.

\section{Calculation method}

\section{$2.1 \mathrm{~GB} / \mathrm{T} 151$}

According to the design method of heat exchangers in China, the thickness of heat exchange tubes should be calculated according to the outer diameter formula in GB150.3-2011[6], and if necessary, the external pressure should be checked. The strength calculation of heat exchange tubes is as follows:

$\delta 1=\mathrm{Pd} /(2 \times \mathrm{S}+\mathrm{P})$

$$
\begin{gathered}
\delta_{1}=\frac{P d}{2 S+P} \\
\delta_{0}=\delta_{1} \times\left(1+\frac{d}{4 R}\right)
\end{gathered}
$$

where:

$\mathrm{P}$ is design pressure, $\mathrm{MPa}$; $\mathrm{S}$ is allowable stress, $\mathrm{MPa}$; $\delta_{0}$ is the minimum thickness before bending, $\mathrm{mm} ; \delta_{1}$ is the thickness required for strength calculation of straight pipe section in GB150.3-2011, mm; $d$ is the outer

*Corresponding author's e-mail: ynduzgz@163.com 
diameter of the heat exchange tube, $\mathrm{mm}$; $\mathrm{R}$ is the bending radius of elbow section, as shown in Figure. 1.

It should be noted that the strength design concept of heat exchange tubes in GB/T 151 is that the thickness of the back wall of bent pipes shall not be less than the calculated thickness of straight pipes. Therefore, the minimum thickness before bending is given in the standard.

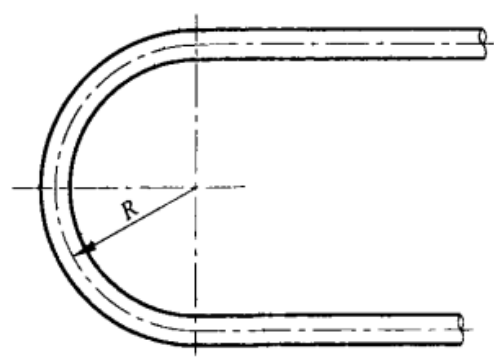

Figure 1. Bending radius of U-tube heat exchange tube R[4]

\subsection{EN12952}

EN 12952 bend strength calculation needs to meet the following requirements:
(1) The actual wall thickness of the straight pipe shall not be less than the calculated thickness of the straight pipe.

(2) The stress on the inside of the elbow should be less than the allowable stress of the material, that is, the minimum wall thickness of the inside of the elbow should be greater than the calculated thickness of the inside of the elbow;

(3) The stress on the outside of the elbow should be less than the allowable stress of the material, that is, the minimum wall thickness on the outside of the elbow should be greater than the calculated thickness on the outside of the elbow.

Then The formula for calculating the minimum calculated wall thickness $e_{\text {ct }}$ of straight pipe could be described as:

$$
e_{c t}=\frac{p_{c} d_{o}}{2 f+p_{c}}
$$

Where:

Here, $e_{\mathrm{r}} \geq e_{\mathrm{ct}}$ should be met, $e_{\mathrm{rt}}$ is the measured minimum wall thickness.

The ratio $r / e_{\mathrm{ct}}$ of the actual bend radius to the minimum calculated wall thickness of the straight pipe could be described as:

$$
\frac{r}{e_{c t}}=\sqrt{\frac{1}{2}\left[\left(\frac{d_{o}}{2 e_{c t}}\right)^{2}+\left(\frac{r_{b}}{e_{c t}}\right)^{2}\right]+\sqrt{\frac{1}{4}\left[\left(\frac{d_{o}}{2 e_{c t}}\right)^{2}+\left(\frac{r_{b}}{e_{c t}}\right)^{2}\right]^{2}-\frac{d_{o}}{2 e_{c t}}\left(\frac{d_{o}}{2 e_{c t}}-1\right)\left(\frac{r_{b}}{e_{c t}}\right)^{2}}}
$$

Thickening coefficient $B_{\mathrm{i}}$ of inner side wall thickness elbow could be described as:

$$
B_{i}=\frac{d_{o}}{2 e_{c t}}+\frac{r}{e_{c t}}-\left(\frac{d_{o}}{2 e_{c t}}+\frac{r}{e_{c t}}-1\right) \sqrt{\frac{\left(\frac{r}{e_{c t}}\right)^{2}-\left(\frac{d_{o}}{2 e_{c t}}\right)^{2}}{\left(\frac{r}{e_{c t}}\right)^{2}-\left(\frac{d_{o}}{2 e_{c t}}\right)\left(\frac{d_{o}}{2 e_{c t}}-1\right)}}
$$

Minimum calculated wall thickness of elbow inside $e_{\text {cti }}$ could be described as:

$$
e_{c t i}=e_{c t} B_{i}
$$

Thickness thinning coefficient of outer side wall elbow $B_{0}$ could be described as:

$$
B_{o}=\frac{d_{o}}{2 e_{c t}}-\frac{r}{e_{c t}}+\left(\frac{d_{o}}{2 e_{c t}}-\frac{r}{e_{c t}}-1\right) \sqrt{\frac{\left(\frac{r}{e_{c t}}\right)^{2}-\left(\frac{d_{o}}{2 e_{c t}}\right)^{2}}{\left(\frac{r}{e_{c t}}\right)^{2}-\left(\frac{d_{o}}{2 e_{c t}}\right)\left(\frac{d_{o}}{2 e_{c t}}-1\right)}}
$$

Stress on the inside of elbow $f_{\text {ai }}$ could be described as:

$$
f_{a i}=\frac{p_{c}\left(d_{o}-e_{r t i}-e_{r t o}\right)}{2 e_{r t i}} \times \frac{2 r_{b}-0.5 d_{o}+1.5 e_{r t i}-0.5 e_{r t o}}{2 r_{b}-d_{o}+e_{r t i}}+\frac{p_{c}}{2}
$$

Here, $e_{\mathrm{rti}}$ is the minimum wall thickness inside the actual elbow; $e_{\text {rto }}$ is the minimum wall thickness on the outside of the actual elbow.
The result of stress evaluation on the inner side elbow should satisfy $f_{\mathrm{ai}} \leq f$.

Stress on the outside of elbow $f_{\text {ao }}$ could be described as: 


$$
f_{a o}=\frac{p_{c}\left(d_{o}-e_{r t i}-e_{r t o}\right)}{2 e_{r t o}} \times \frac{2 r_{b}+0.5 d_{o}+0.5 e_{r t i}-1.5 e_{r t o}}{2 r_{b}+d_{o}-e_{r t o}}+\frac{p_{c}}{2}
$$

The evaluation results of stress on the outside of elbow should meet: $f_{\text {ao }} \leq f$.

\subsection{Principle of EN12952}

The theoretical basis for strength calculation of elbow in Appendix A of EN 12952 is:
Under the action of internal pressure load, the stress on the inner side wall of elbow with equal wall thickness is greater than that on the outer side wall of elbow. The elbow with equal wall thickness of $90^{\circ}$ is as example. $R$ is bending radius, $d$ is inner diameter, $T$ is wall thickness. The condition of physical balance by infinitesimal elements could be described as:

$$
2 \sigma_{\beta} \times \sin \left(\frac{\Delta \beta}{2}\right) \rho_{1} \Delta \alpha \mathrm{t}+2 \sigma_{z} \times \sin \left(\frac{\Delta \alpha}{2}\right) \rho_{2} \Delta \beta \mathrm{t}=\mathrm{P} \rho_{1} \rho_{2} \Delta \alpha \Delta \beta
$$

Where $\rho_{2}$ is the circumferential radius of curvature and $\rho 1$ is the axial radius of curvature.

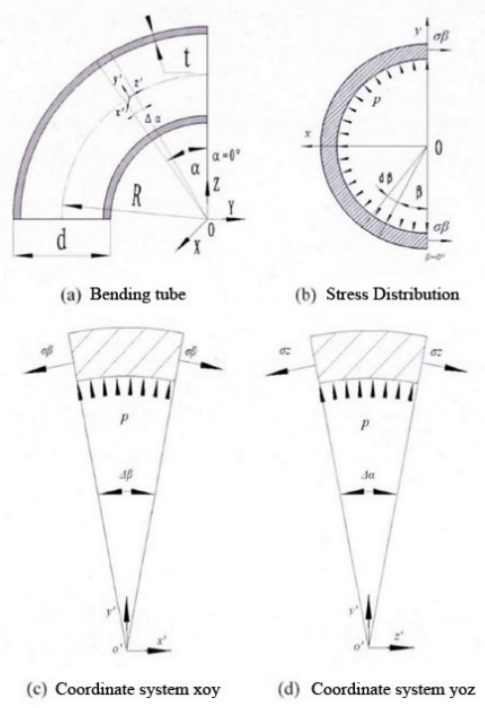

The geometric relationship could be described Figure

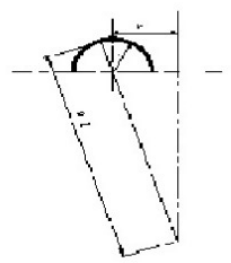

(e)

Figure 2. Geometric relationship

According to the geometric relationship in Figure2:

$$
\begin{gathered}
\rho_{1}=r \\
\rho_{2}=\frac{(\mathrm{R}-\mathrm{r} \cos (\beta))}{\sin \left(\beta-\frac{\pi}{2}\right)}
\end{gathered}
$$

Balance condition by axial section force could be described as:

$$
\begin{gathered}
P \pi r^{2}=2 \sigma_{z} \pi r t \\
\sigma_{z}=\frac{\operatorname{Pr}}{2 t}
\end{gathered}
$$

The physical balance equation with micro-elements could be described as:

$$
\sigma_{\beta}=\frac{\operatorname{Pr}}{2 t} \times\left(2+\frac{r \cos (\beta)}{R-r \cos (\beta)}\right)
$$

The axial stress distribution in thin-walled elbow with equal wall thickness is consistent with that in straight pipe, but the circumferential stress distribution is the same as that in straight pipeßAngular correlation.

\section{Calculation}

\subsection{Initial conditions}

In this section, taking the serpentine pipe project being manufactured in the actual factory as an example, the strength calculation results of heat exchange tubes under two different algorithms are given in Table 1. The nominal size of the selected heat exchange tube is $\phi 25 \times 3.4 \mathrm{~mm}$, and the measured data of the bent pipe are $2.8 \mathrm{~mm}$ on the outer wall and $3.2 \mathrm{~mm}$ on the inner wall.

Table 1. Design parameters

\begin{tabular}{llcl}
\hline Name & Code & Value & Unit \\
\hline Design Pressure & $P$ & 43 & $\mathrm{MPa}$ \\
Design Temperature & $T$ & 231 & ${ }^{\circ} \mathrm{C}$ \\
Material & & $15 \mathrm{Mo3}$ & \\
Allowable Stress & $S$ & 151.7 & $\mathrm{MPa}$ \\
Outer Diameter & $d$ & 25 & $\mathrm{~mm}$ \\
Bend Radius & $R$ & 82.5 & $\mathrm{~mm}$ \\
\hline
\end{tabular}




\section{$3.2 \mathrm{~GB} / \mathrm{T} 151$}

Strength calculation thickness of straight pipe section: $\delta_{1}=\mathrm{Pd} /(2 \times \mathrm{S}+\mathrm{P})=3.103 \mathrm{~mm}$

Minimum thickness before bending pipe $\delta_{0}=\delta_{1} \times(1+\mathrm{d} / 4 / \mathrm{R})=3.34 \mathrm{~mm}$

The minimum thickness of straight pipe selected for design is $3.34 \mathrm{~mm}$.

\subsection{EN 12952}

Calculation by substituting it into the formula:

The measured minimum wall thickness $e_{\mathrm{rt}}=3.2 \mathrm{~mm}$, the calculated minimum wall thickness $e_{\mathrm{ct}}=3.1 \mathrm{~mm}$.

The minimum calculated wall thickness of elbow is $3.37 \mathrm{~mm}$.

The minimum calculated wall thickness of elbow is $2.89 \mathrm{~mm}$.

Measured stress $f_{\mathrm{ai}}=150 \mathrm{MPa} \leq \mathrm{S}$.

The stress on the outside of the bend is $f_{\text {ao }}=151 \mathrm{MPa}$.

Compared with the national standard, the wall thickness of $3.1 \mathrm{~mm}$ calculated by EN12952 could meet the requirements, which is $7.7 \%$ thinner than that of the national standard. At the same time, the stable bending process is needed as the support condition in the calculation process.

\section{Conclusions}

This paper systematically studies the calculation methods of serpentine pipe at home and abroad. By comparing the actual serpentine projects, it is found that EN12952 standard could be used for calculation, and the pipe diameter with wall thickness of $3.1 \mathrm{~m}$ can meet the requirements, which is $7.7 \%$ thinner than that of the national standard. However, a stable bending process is needed as the supporting condition, because the actual bending data is required in the calculation process of EN12952.

\section{Acknowledgments}

This study has received funding by Scientific Research Projects of Shanghai Quality and Technical Supervision (2019-22), and Shanghai Science and Technology Talents Program (19XD1432600). The authors are grateful for the financial supports provided by Shanghai engineering research center of pressure pipeline intelligent inspection and National Heat Exchanger Product Quality Inspection Center.

\section{References}

1. Zhu, J. W. (2017) Structural characteristics and manufacturing process analysis of serpentine tube high pressure heater. Energy Research and Information, 33 (2): 92-95.

2. Gu, Y. X., Wang, SP., Yang, SM., et al (2013) Thermal economic analysis of ultra supercritical secondary reheat generator set. Thermal Power Generation, 42 (9): 7-9.

3. Zhao, W. C.. (2017) Overall design and economic analysis of 1 MW ultra supercritical secondary Reheat Unit. Science and Technology Wind, (21): 228-228.

4. GB/T151-2014. Heat exchangers [S]. 2014.

5. EN12952-2015. Water-tube boileres and auxiliary installations [S]. 2015.

6. GB/T150-2011. Pressure vessels [S]. 2011. 